\title{
DESAFIOS DE PROFESSORES INICIANTES DE CIÊNCIAS E BIOLOGIA
}

\author{
Apresentação: Comunicação Oral \\ SILVA, Wanieverlyn de Lima ${ }^{1}$; ARAÚJO, Monica Lopes Folena ${ }^{2}$.
}

\section{Resumo}

O início de qualquer carreira pode apresentar-se repleto de desafios. As novas descobertas, convívio e decisões do dia a dia são experiências que o profissional precisa aprender a lidar. Nesse sentido, a carreira docente assemelha-se a de outras profissões, porém existem várias particularidades inerentes à profissão de professor. Dessas particularidades, podem surgir desafios que são exclusivos dessa classe de profissionais. O estudo atual faz parte da construção de uma dissertação sobre os desafios de professores de Ciências e Biologia em início da carreira. Nesse artigo compartilhamos os resultados do estudo piloto feito com professores com mais de dez anos de carreira, no qual eles expõem suas experiências e nos falam sobre os principais desafios que enfrentaram no início de sua carreira docente. Os professores ouvidos também falaram sobre a fase de transição entre ser estudante e se tornar professor regular da sala de aula, sobre a contribuição da formação inicial e a contribuição da instituição que lecionou. Trata-se de uma pesquisa qualitativa, realizada por meio de questionário estruturado e entrevista. Discorremos sobre os resultados dialogando com autores como Nóvoa (1992), Tardif (2002) e Garcia (2011). Os principais desafios mencionados pelos professores foram em torno de três eixos: relação professor-aluno, desafios com a família e desafios infraestruturais. Quando indagados pelos desafios da área específica - Ciências e Biologia, os docentes mencionaram como desafios: falta de interesse dos estudantes, pouco tempo para resgatar conteúdos anteriores, falta de material de laboratório e falta de domínio do conteúdo por parte do professor iniciante. Os professores participantes sugeriram estratégias para minimizar as dificuldades do início da carreira, as agrupamos considerando três aspectos: como ensinar, como se relacionar com os estudantes e apreciar a profissão e área escolhida.

Palavras-Chave: Desafios, professores iniciantes, ciências, biologia.

\section{Introdução}

Ser professor é um desafio nos dias atuais, pois várias são as responsabilidades inerentes à essa profissão. Toda carreira, seja de qualquer área do conhecimento, tem seu início. O início pode ser determinante para a continuidade.

Responsabilidades consideradas simples por alguns professores com anos de docência, como: preencher uma caderneta, preparar um exame ou uma avaliação ou fazer a chamada, podem apresentar-se como desafios para professores recém-formados. É preciso dar atenção a

\footnotetext{
${ }^{1}$ Mestranda em Ensino de Ciências, Universidade Federal Rural de Pernambuco, wanylimas@gmail.com

2 Professora do Departamento de Educação e do Programa de Pós-Graduação em Ensino das Ciências, Universidade Federal Rural de Pernambuco, monica.folena@gmail.com
} 
esses e outros desafios, para que o início da carreira não se torne o motivo da desistência da profissão, pois sabemos que essa é uma carreira necessária e insubstituível. É importante entender o que significa um desafio.

Segundo o dicionário online de português, desafio pode ser, entre outras definições: “o ato ou efeito de desafiar; a convocação para todo tipo de jogo, competição, disputas; ocasião ou grande obstáculo que deve ser ultrapassado". Nesse contexto, é notório que desafio está relacionado a algo novo, algo que ainda não feito por determinada pessoa que é agora desafiada a fazer ou algo que apresente uma dificuldade considerável para que seja realizado. Assim também pode ser considerada a entrada na carreira, um novo desafio para o recémformado.

Nesse contexto, surgiu o problema que tem sido o norte dessa pesquisa: quais desafios os professores de Ciências e Biologia enfrentam no início da sua carreira? Essa pergunta surgiu da nossa experiência enquanto professora do ensino regular em uma escola privada dotada de limitações. Essa vivência no ambiente escolar nos fez reconhecer que o início da carreira é uma fase difícil, principalmente quando não há um acompanhamento específico por parte da escola. Outras pontos relevantes serão discutidos aqui: a contribuição da formação inicial e da escola campo, desafios da área específica ciências/biologia.

Para discorrer sobre o início da carreira e as fases que o acompanham iremos nos fundamentar em Nóvoa (1992), que apresenta estágios do início da carreira. Tardif (2002) afirma que o início da carreira é uma fase crítica. Pesquisas recentes, como a de Mira e Romanowski (2014) investigaram quantos programas de inserção profissional para professores iniciantes existem, e os resultados indicam que existem poucos programas.

Se o campo de trabalho do professor é o ensino, é mister que ele seja preparado para isso. Essa preparação pode acontecer na formação inicial, mas a escola que recebe um professor novato pode contribuir oferecendo apoio e acompanhamento. Assim, como acontece na medicina, por exemplo, um médico cirurgião recém-formado não fará sua primeira intervenção cirúrgica sozinho, visto que ele precisa passar por uma residência e será acompanhado por médicos mais experientes. Em outras profissões acontece o mesmo. Mas não vemos isso com frequência em relação ao ingresso dos professores nas escolas, raramente ouvimos falar sobre programas de acompanhamento.

Estreitamos nossa visão para professores de Ciências e Biologia, porque segundo Cachapuz (2005), a necessidade de uma Educação científica é urgente, essencial para o desenvolvimento social e pessoal. Somos testemunhas de uma evolução no campo científico e tecnológico, novas técnicas para tratamento de doenças, novas descobertas no corpo humano 
e no ambiente, dentre muitas novidades da área das Ciências da Natureza. A própria evolução da tecnologia pode ser um desafio para os professores dialogarem sobre isso no ambiente escolar. Mas será que os docentes enxergam desafios na sua área específica, ou os desafios são os mesmos para todos os professores?

Buscando responder a essa e outras questões, discutiremos sobre o trabalho docente, formação inicial e os desafios que os docentes de ciências e biologia enfrentam no seu dia a dia. Entrevistamos professores com mais de dez anos de profissão para sondá-los sobre o início de suas carreiras, seguimos com uma análise do conteúdo dessas entrevistas, com base na metodologia utilizada por Bardin (2002). Ratificando que o presente trabalho traz resultados de um estudo piloto, parte de uma dissertação sobre o tema abordado. Pretendemos por meio desse artigo, valorizar a função do professor e identificar desafios do dia a dia.

\section{Fundamentação Teórica}

O trabalho em geral e o trabalho do professor apresentam características diferentes entre si. De acordo com Tardif (2002, p. 112) "existem, atualmente, instrumentos conceituais e metodológicos bem elaborados que possibilitam analisar o trabalho de um modo geral e o trabalho docente em particular". Nas instituições escolares é possível analisar como o professor trabalha e como o conhecimento é compartilhado entre os alunos, enfim é possível analisar a função social do professor.

É no primeiro emprego que o docente irá exercer sua função e definir o seu perfil enquanto educador. Segundo estudos de Nóvoa (1992), vários fatores podem afetar a vida de um professor no início de sua carreira, podendo inclusive fazê-lo desistir da profissão. Um desses fatores é a responsabilidade em assumir a carreira docente, pois esta tem função social relevante e se apresenta repleta de desafios. Trata-se ainda de uma carreira desprestigiada nacionalmente e que exige, como destaca Tardif (2002), que os professores se apropriem de distintos saberes para contribuir na formação de seus estudantes. O autor destaca que:

\footnotetext{
Entretanto a relação dos docentes com os saberes não se reduz a uma função de transmissão de conhecimentos já constituídos. Sua prática integra diferentes saberes, com os quais o corpo docente mantém diferentes relações. Pode-se definir o saber docente como um saber plural, formado pelo amálgama, mais ou menos coerente, de saberes disciplinares, curriculares e experienciais. (Idem, p. 36)
}

Esse conjunto de saberes envolve o professor e, para o professor iniciante, pode tornar-se mais difícil a apropriação, dependendo de como foi sua formação inicial e de como é a sua recepção na escola. Assim, destacamos a importância da formação inicial na construção de saberes específicos e pedagógicos e a relevância do campo de trabalho, ou seja, a escola, 
orientar e contribuir na consolidação da formação inicial, sendo um alicerce para o professor em início de carreira. Afinal, não é coerente que esse professor sinta-se sozinho diante de tantos desafios e responsabilidades inerentes à carreira docente.

Em pesquisa recente, realizada pela Fundação Lemann em 2014, cujo objetivo foi divulgar a visão dos professores sobre a Educação no Brasil, é possível entender como os docentes se sentem sobre alguns aspectos. Segundo a pesquisa, os aspectos que mais trazem satisfação para os professores é o fato de estarem contribuindo para o aprendizado dos alunos e por entenderem sua responsabilidade social, ou seja, eles reconhecem o valor social da educação. Em contrapartida, as condições de trabalho, remuneração e o reconhecimento da sociedade em geral ficaram com menor porcentagem em relação a satisfação, isso comprova que o professor está rodeado de desafios, ele se sente desvalorizado enquanto profissional. Observemos a fala de uma professora da rede estadual: "Tem aluno que já me perguntou "você só da aula? Você não trabalha?" Ao contrário dessa fala, Gadotti (2002, p.9) afirma que,

Ser professor hoje é viver intensamente o seu tempo com consciência e sensibilidade. Não se pode imaginar um futuro para a humanidade sem educadores. Os educadores, numa visão emancipadora, não só transformam a informação em conhecimento e em consciência crítica, mas também formam pessoas.

Os professores são essenciais, o fato é irrefutável. Porém, muitas vezes a desvalorização profissional do trabalho docente torna-se fator de desestímulo, não basta olhar para a prática do professor em sala de aula, mas para os demais fatores que envolvem o contexto escolar. Tardif e Lessard (2007) afirmam que o estudo da docência entendida como um trabalho continua negligenciado. Segundo eles,

O perigo que ameaça a pesquisa sobre a docência e, mais amplamente, toda a
pesquisa sobre a educação, é o perigo da abstração: elas se fundamentam as mais das
vezes sobre abstrações - a pedagogia, a didática, a tecnologia do ensino, o
conhecimento, a cognição, a aprendizagem, etc. - sem levar em consideração
fenômenos como o tempo de trabalho dos professores, o número de alunos, suas
dificuldades e suas diferenças, a matéria a cobrir e sua natureza, os recursos
disponíveis, as dificuldades presentes, a relação com os colegas de trabalho, com os
especialistas, os conhecimentos dos agentes escolares, o controle da administração, a
burocracia, a divisão e a especialização do trabalho, etc. (Idem, p. 24)

Retomando a pesquisa da Fundação Lemann, segundo os professores participantes, os fatores que mais impactam no cotidiano escolar são: falta de acompanhamento psicológico para os alunos que precisam, indisciplina dos alunos e defasagem de aprendizado de alunos. Essas respostas confirmam que muitos fatores precisam ser considerados para que o trabalho do professor seja produtivo.

O trabalho docente foi precedido de uma formação para habilitá-lo nessa profissão. Coelho (2003) considera a formação de professores como um trabalho complexo, pois está 
sempre em construção, não é algo pronto. Conforme o autor, a formação de professores "extrapola os limites da universidade, do curso, do currículo, da formação inicial nas licenciaturas e se estende pela realização da tarefa, da obra de educar, de ensinar" (p. 57). A formação de professores é na verdade uma formação de formadores, porque futuramente, esses docentes formados também irão formar, por isso a relevância de tal processo formativo.

\begin{abstract}
Quando se trata de educação escolar são os professores que propiciam essa intermediação. Então, a formação de quem vai formar torna-se central nos processos educativos formais, na direção da preservação de uma civilização que contenha possibilidades melhores de vida e co participação de todos. Por isso, compreender e discutir a formação, as condições de trabalho e carreira dos professores, e, em decorrência sua configuração identitária profissional, se torna importante para a compreensão e discussão da qualidade educacional de um país, ou de uma região. (GATTI, 2016, p. 163)
\end{abstract}

Segundo Garcia,

o conceito de formação tem a ver com a capacidade de formação, assim como a vontade de formação. Quer dizer, é o indivíduo, a pessoa, o responsável último pela activação e desenvolvimento de processos formativos. Isto não quer dizer, que a formação seja necessariamente autônoma. É através da interformação que os sujeitos - neste caso os professores - podem encontrar contextos de aprendizagem que favoreçam a procura de metas de aperfeiçoamento pessoal e profissional. (1999, p. 22)

Entendemos, portanto, que a formação precisa ser estudada e discutida no âmbito institucional, mas que formação também é um processo pessoal do indivíduo. Sendo assim, a formação dos professores deve preparar, o melhor possível, o docente para a carreira.

Segundo Nóvoa (1999) existem várias maneiras de estruturar o ciclo de vida dos professores, existem fases na carreira docente que precisam ser consideradas, essas não são vividas do mesmo modo por todos os professores. Ele considera a fase chamada "de exploração", que é uma opção provisória na qual o professor em início de carreira experimenta um ou mais papéis, e a fase "de estabilização", também chamada de compromisso "na qual as pessoas centram a sua atenção no domínio das diversas características do trabalho, na procura de um setor de focalização ou de especialização" (p. 37). O autor concorda que "a fase de exploração ou das opções provisórias desemboca naquilo que, ao invés, se designa pelo estádio do comprometimento definitivo ou da estabilização e da "tomada de responsabilidades". Essas fases podem ser diferentes para cada profissional, alguns podem nunca sair da fase de exploração ou estabilização. "O desenvolvimento de uma carreira é, assim, um processo e não uma série de acontecimentos. Para alguns, este processo pode parecer linear, mas, para outros, há patamares, regressões, becos sem saída, momentos de arranque, descontinuidades" (NÓVOA, 1992, p. 38). A entrada na carreira é frequentemente marcada por dois estágios: sobrevivência e de descoberta. O estágio de "sobrevivência" caracteriza o "choque do real", 
a confrontação inicial com a complexidade da situação profissional: o tatear constante, a preocupação consigo próprio (Estou-me a aguentar?), a distância entre os ideais e as realidades quotidianas da sala de aula, a fragmentação do trabalho, a dificuldade em fazer face, simultaneamente, à relação pedagógica e à transmissão de conhecimentos, a oscilação entre relações demasiado íntimas e demasiado distantes, dificuldades com alunos que criam problemas, com material didático inadequado, etc. (NÓVOA, 1992, p. 39)

Enquanto o estágio de descoberta é caracterizado pelo "entusiasmo inicial, a experimentação, a exaltação por estar, finalmente, em situação de responsabilidade, por se sentir colega num determinado corpo profissional" (Idem, p.39). Esses estágios podem acontecer simultaneamente ou um sobressair sobre o outro, variando de professor para professor. Podemos observar que o início da carreira é marcado por vários acontecimentos que vale refletir. Garcia (1999) denomina a fase que compreende os primeiros anos de docência por fase de iniciação ao ensino, que faz parte de uma formação como processo contínuo, sistemático e organizado. Em pesquisa citada por André (2012) foi constatado que a taxa de evasão do magistério é maior no início da carreira docente.

É importante olhar para a formação de cada área do conhecimento para sondar as particularidades de cada processo formativo. No caso, de Ciências e Biologia, nos questionamos: por que formar professores de Ciências e Biologia? Qual a importância dessa formação para a sociedade em geral? Moraes e Mancuso (2006, p. 44) ao discutirem sobre o ensino de ciências como eixo importante na formação de crianças, adolescentes e jovens, afirmam que "aprendizagens significativas e consistentes nesse campo do conhecimento humano podem proporcionar o desenvolvimento de novas consciências e ampliar de forma mais plena as potencialidades da vida na sociedade e no ambiente". Para promover aprendizagens significativas o professor precisa de formação.

o ensino de Ciências da Natureza tem compromisso com uma formação que prepare o sujeito para interagir e atuar em ambientes diversos, considerando uma dimensão planetária, uma formação que possa promover a compreensão sobre o conhecimento científico pertinente em diferentes tempos, espaços e sentidos; a alfabetização e o letramento científicos; a compreensão de como a ciência se constituiu historicamente e a quem ela se destina; a compreensão de questões culturais, sociais, éticas e ambientais, associadas ao uso dos recursos naturais e à utilização do conhecimento científico e das tecnologias (BRASIL, BNCC, p.149)

Nesse sentido, Cachapuz (2005, p. 19) afirma que "a educação científica converteu-se, na opinião dos especialistas, numa exigência urgente, num fator essencial do desenvolvimento das pessoas e dos povos, também a curto prazo". No contexto atual, os professores tem presenciado o avanço da tecnologia e da ciência, isso nos leva a refletir que podem existir desafios particulares desse grupo de professores frente às inovações na sociedade. 


\section{Metodologia}

Trata-se de uma pesquisa qualitativa, que segundo Godoy (1995, p.58) "não procura enumerar e/ ou medir os eventos estudados, nem emprega instrumental estatístico na análise dos dados. Parte de questões ou focos de interesses amplos, que vão se definindo à medida que o estudo se desenvolve". Nesse sentido, a presente pesquisa se interessou em dar voz aos professores, que fizeram parte de um estudo piloto, que "é uma miniversão do estudo completo, que envolve a realização de todos os procedimentos previstos na metodologia de modo a possibilitar alteração/melhora dos instrumentos na fase que antecede a investigação em si.” (BAILER; TOMITCH; D’ELY, 2011, p. 129).

$\mathrm{Na}$ pesquisa qualitativa considera-se tanto o processo quanto o produto, porém aliados ao significado e implicações dos resultados da pesquisa, com o mesmo rigor científico que outros tipos de pesquisas exigem. Neves $(1996$, p. 1) se refere a esse tipo de pesquisa como "promissora possibilidade de investigação".

Nosso campo de estudo foi uma escola pública estadual da cidade do Recife - PE, e os atores sociais foram três professores que lecionam ciências e/ou biologia na referida escola, todos com mais de dez anos de carreira.

Utilizamos como instrumentos de pesquisa o questionário semiestruturado e a entrevista com cada docente. O questionário serviu para caracterização dos atores sociais, eles preencheram sua idade, sexo, formação, tipos de escolas que lecionam e o tempo que exercem a docência. Já na entrevista, dialogamos sobre o momento de transição entre ser estudante e se tornar professor, sobre o sentimento após os primeiros dias como docente, sobre os desafios do início da carreira, sobre a contribuição da formação inicial e da escola que recepcionou esse docente na primeira vez e sobre os desafios da área específica. Além disso, os professores tiveram a oportunidade de propor sugestões e/ou estratégias para que os professores de Ciências e Biologia enfrentem menos problemas e/ou dificuldades no início da carreira.

As entrevistas foram audiogravadas, posteriormente transcritas e analisadas à luz da análise de conteúdo, considerando as seguintes etapas propostas por Bardin (2002): préanálise, exploração do material, tratamento dos resultados (codificação e categorização), inferência e interpretação.

\section{Resultados e Discussão}

Os professores tem em média 47 anos de idade, são duas professoras e um professor, totalizando três docentes. Todos eles possuem especialização, dois na área das Ciências e uma 
em Psicopedagogia e Gestão escolar. Eles lecionam apenas na Educação Básica - pública, e tem mais de dez anos na profissão. Identificaremos, a partir de agora, os professores por P seguido por um número: P1, P2 e P3.

Quando perguntados sobre o momento de transição entre ser estudante e se tornar professor, surgiram as seguintes respostas: susto, pânico, insegurança, conflito, e apenas P3 relatou que foi um momento de felicidade. Essas respostas coincidem com dois estágios do início da carreira propostos por Nóvoa (1992), o de sobrevivência e de descoberta. No estágio de sobrevivência o professor vivencia o choque do real, a confrontação inicial com a complexidade da situação profissional e ele também pode comparar a prática com o que aprendeu na sala de aula, como foi o caso de P2 "A gente entra em conflito, o que a gente aprende na universidade com a prática". Sobre a experiência de P1 "Foi um susto, porque você vê aquela turma todinha conversando, você falando e eles não dando atenção". Foi possível perceber que houve uma expectativa de como seria o trabalho, mas como toda pessoa inexperiente pode sentir insegurança. "No início é aquela questão de insegurança, do que vai ser o trabalho, de como vai ser, do público"(P2). P1 ainda afirmou que "o primeiro momento é sempre pânico, você tem que respirar fundo e acalmar pra pensar no segundo passo".

Em contrapartida P3 se mostrou realizado com seu primeiro contato como professor de uma instituição: "Pra mim foi maravilhoso, o meu professor da universidade preparou bem a gente". P3 vivenciou o estágio de descoberta, que consiste no entusiasmo inicial, no qual o docente se sente parte do corpo profissional, o fato de ter sua sala de aula, os seus alunos, o seu programa (NÓVOA, 1992).

Com muita frequência, a literatura empírica indica que esses dois aspectos, o da sobrevivência e o da descoberta são vividos em pararelo e é o segundo aspecto que permite aguentar o primeiro. Mas verifica-se, igualmente, a existência de perfis com uma só destas componentes impondo-se como dominante. (Idem, p. 39)

Em relação ao sentimento após os primeiros dias de aula, a resposta dos professores encontra-se na tabela abaixo:

Tabela 1: Sentimentos após os primeiros dias de aula como docentes regulares. Fonte: Própria

\begin{tabular}{|c|c|r|c|}
\hline Professor & Sentimento & Unidade de contexto (trecho) & Inferência \\
\hline \multirow{2}{*}{ P1 } & Tristeza & $\begin{array}{r}\text { "Me senti muito triste, saí até com vontade } \\
\text { de chorar, chorava só em casa para os } \\
\text { alunos não verem". }\end{array}$ & Experiência negativa \\
\hline P2 & Perplexidade & $\begin{array}{r}\text { "Fiquei surpresa com a forma dos alunos, } \\
\text { a questão da falta de interesse mesmo em }\end{array}$ & Experiência negativa \\
\hline P3 & Felicidade & "Me senti ótimo". & Experiência positiva \\
\hline
\end{tabular}


Em pesquisa realizada por Aragão (2008, p. 35) constatou-se que 90\% dos professores indicam o salário e o desgaste emocional como principais motivos para mudar de profissão. Então não devemos negligenciar os fatores que envolvem o contexto físico e emocional dos professores, principalmente no início da carreira. Os três professores entrevistados afirmaram que a escola que os recebeu pela primeira vez não ofereceu nenhum tipo de acompanhamento por estarem no início da carreira. Isso dificulta ainda mais o trabalho do professor iniciante. Provavelmente, se os professores participassem de algum programa ou curso específico no início da carreira, sentiriam menos dificuldades e insegurança no cotidiano da escola. $\mathrm{O}$ apoio que um deles mencionou foi dado por professores mais experientes. "Na realidade o apoio que tem é um dando ao outro, quem chegar aqui, por exemplo eu pergunto se quer algum material ou se está precisando de alguma coisa, mais entre a gente (P2).

\begin{abstract}
Vários professores dizem ter-se beneficiado, no início da carreira ou na atribuição de uma nova função, com o suporte de um colega de experiência, como uma espécie de mentor informal. Essa colaboração parece ter sido extremamente preciosa para esses professores. Às vezes, os noviços procuram um professor experiente para pedir dicas ao seu planejamento, sua pedagogia, seu modo de trabalhar. Em certos casos, os professores experientes precisam ajudar os jovens a preencher as lacunas de sua formação universitária. (TARDIF; LESSARD. 2007, p. 185)
\end{abstract}

Os desafios mencionados pelos docentes podem ser visto na tabela a seguir:

Tabela 2: Desafios de professores no início da carreira. Fonte: Própria

\begin{tabular}{|c|c|c|}
\hline Professores & Desafios do início da carreira & Categorias elaboradas \\
\hline P1 & Despertar a atenção do aluno & Relação professor-aluno \\
\hline P1 & Propor atividades diferenciadas & Relação professor-aluno \\
\hline & Estimular o aluno & Relação professor-aluno \\
\hline P2 & Falta de material & Infraestrutura da escola \\
\hline P2 & Baixo salário & Sistema salarial \\
\hline P2 & Falta de educação familiar & Falta de presença da família \\
\hline P3 & Preconceito & Relação professor-aluno \\
\hline
\end{tabular}

Foi possível perceber que a maioria dos desafios são provenientes das relações entre professor e alunos. A aprendizagem e a relação com os alunos são desafios para o professor, aí repousa a maior parte de sua preocupação. Na pesquisa realizada pela Fundação Lemann (2014), foram identificados quatro grandes temas que preocupam os professores: a formação efetiva do aluno, a heterogeneidade das turmas, a relação com as famílias e a aplicabilidade das políticas educacionais. Segundo essa pesquisa, os professores tem assumido tarefas que 
deveriam ser assumidas pelos pais. É necessária a participação da família, é preciso ampliar o diálogo.

P1, P2 e P3 afirmaram que houve contribuição da formação inicial, que serviu como uma base, mas a prática muitas vezes é diferente. "Contribuiu, agora assim em termos de conteúdo, de aprendizagem lá. Agora de prática, só chão de escola mesmo” (P2).

Os professores, por espontânea vontade, não mencionaram desafios da área específica, Ciências e/ou Biologia, por isso questionamos os mesmos acerca disso. Segundo eles, existem e são os seguintes: resgatar conteúdos anteriores, alunos desinteressados, tempo curto para a quantidade de conteúdos específicos em comparação com outras disciplinas, falta de material e falta de domínio do conteúdo. "Existe, porque infelizmente o aluno não tem base. Ele vai de um ano pra outro e não se lembra mais do assunto, então você tem que resgatar aquilo, você perde muito tempo". Pressupomos que o motivo pelo qual os docentes não lembraram dos desafios da área específica se dá pelo fato dos outros desafios estarem se sobressaindo.

Por fim, os docentes sugeriram estratégias para os professores recém-formados, para que eles enfrentem menos dificuldades no início da carreira, figura 1.

Figura 1: Sugestões e estratégias para professores iniciantes. Fonte: Própria

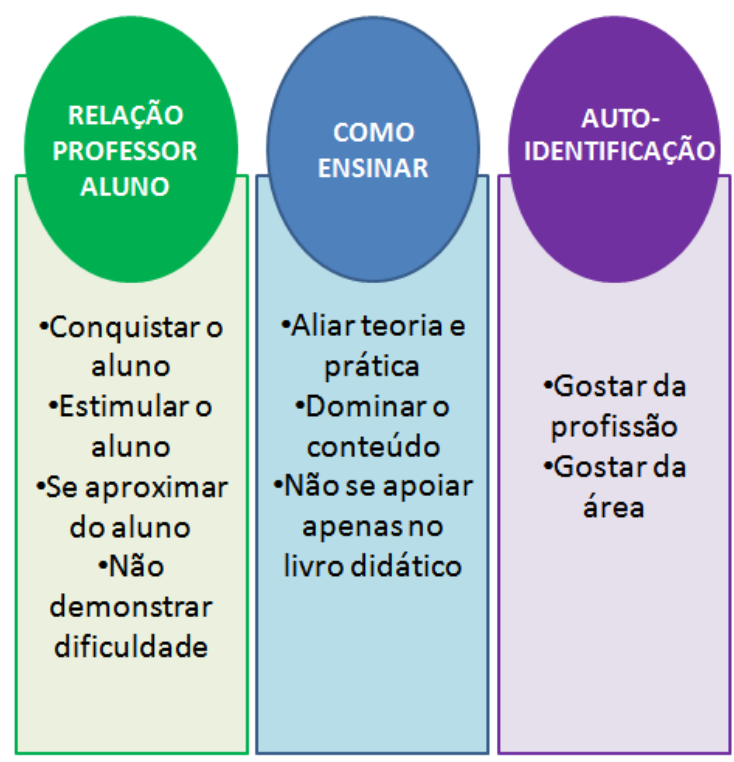

Os professores participantes são muito experientes, eles sugeriram para os novatos que atentasse para a relação com seus alunos, pois é de fundamental importância. "O conselho que eu dou é sempre tentar usar a linguagem deles, tentar chegar o mais próximo possível deles" (P2). Como o professor vai ensinar, é importante que ele saiba aliar aulas práticas com teóricas, estudar e dominar o conteúdo e não se apoiar apenas no livro didático. Por fim, é 
necessário gostar da profissão e da área escolhida, quando fazemos o que gostamos tudo se torna mais fácil.

\section{Conclusões}

Constatamos com este estudo piloto, que os professores precisam enfrentar bastante desafios, relacionados a vários aspectos, como a relação com seus alunos, a falta que faz a família no acompanhamento do aluno e aspectos infraestruturais.

Os desafios são como obstáculos, que para serem vencidos, precisam ser ultrapassados. Os professores precisam refletir sobre esses desafios e escolherem novas posturas diante deles. Além disso, o sistema educacional em geral deve ouvir mais a voz dos professores, para que seu trabalho seja produtivo e para que o docente se sinta valorizado.

Verificamos que o início da carreira pode ser bom para alguns, mas para outros é um momento de muitas dificuldades, acompanhamento e mais pesquisas são necessários.

\section{Referências}

ANDRÉ, Marli. Políticas e programas de apoio aos professores iniciantes no Brasil. Cadernos de Pesquisa v.42 n.145 p.112-129 jan./abr. 2012. Disponível em: < http://www.scielo.br/pdf/cp/v42n145/08.pdf> Acesso: 18 fev. 2016.

ARAGÃO, Maria Sofia César de. A educação dos próximos dez anos: perspectivas para a educação privada no Município de São Paulo. São Paulo: SINPRO-SP, 2008.

BAILER, Cyntia; TOMITCH, Leda Maria Braga; D’ELY, Raquel Carolina Souza. Planejamento como processo dinâmico: a importância do estudo piloto para uma pesquisa experimental em linguística aplicada. Revista Intercâmbio, v. XXIV: 129-146, 2011. São Paulo: LAEL/PUCSP. ISSN 2237-759x.

BARDIN, Laurence. Análise de conteúdo. Lisboa: Edições 70, 1977.

BRASIL, Base Nacional Comum Curricular, 2015. Disponível em: < http://basenacionalcomum.mec.gov.br/> Acesso: 10 jan 2016.

Dicionário online de português. Disponível em: $<<$ https://www.dicio.com.br/desafio/ $>>$ Acesso: 2 out 2016. 
CACHAPUZ António et al. A necessária renovação do ensino das ciências. São Paulo: Cortez, 2005.

COELHO, Ildeu Moreira. Repensando a formação de professores. Nuances: estudos sobre educação - ano IX, v.09, ns 9/10, jan./jun. e jul./dez. 2003.

Fundação Lemann. Conselho de classe: a visão dos professores sobre a educação no Brasil. $2015 . \quad$ Disponível em: <http://www.fundacaolemann.org.br/uploads/estudos/conselho_de_classe_notas_tecnicas_e_d etalhamento_das_questoes.pdf> Acesso: 30 set 2016.

GODOY, Arilda Schmidt. Introdução à pesquisa qualitativa e suas possibilidades. Revista de Administração de Empresas. São Paulo, v. 35, n. 2, p. 57-63.Mar/Abr 1995. Disponível em: < http://www.scielo.br/scielo.php?pid=S0034-75901995000400008\&script=sci_arttext > Acesso em: 10 jan 2016.

GARCIA, Carlos Marcelo. Formação de professores. Para uma mudança educativa. Porto, Portugal: Porto Editora, 1999.

MIRA, Marília Marques; ROMANOWSKI, Joana Paulin. Programas de inserção profissional para professores iniciantes: uma análise da produção científica do IV Congresso Internacional Sobre Professorado Principiante e Inserção Profissional à Docência. X ANPED SUL, Florianópolis, 2014.

MORAES, Roque; MANCUSO, Ronaldo. Educação em Ciências : produção de currículo e formação de professores. 2 ed. Ijuí: Ed. Unijuí, 2006. 304p. (Coleção educação em ciências)

NEVES, José Luiz. Pesquisa qualitativa: características, usos e possibilidades. Cadernos de pesquisas em administração. São Paulo, v.1, n.3, 1996. Disponível em: <http://www.ead.fea.usp.br/cad-pesq/arquivos/C03-art06.pdf> Acesso em 20 out. 2014.

NÓVOA, Antonio. (Org.) Vidas de professores. 2.ed. Porto: Porto Editora, 1992.

TARDIF, Maurice. Saberes docentes e formação profissional. Petrópolis, RJ: Vozes, 2002.

TARDIF, Maurice; LESSARD, Claude. O trabalho docente: elementos para uma teoria da docência como profissão de interações humanas. 3. ed. Petrópolis, RJ: Vozes, 2007. 